\title{
Uma análise da estrutura espacial dos indicadores socioeconômicos do nordeste brasileiro (2000-2010)
}

Keuler Hissa-Teixeira. Universidade Federal de Alagoas, Maceió, Brasil.

RESUmo | Embora, a pobreza e a desigualdade de renda na região Nordeste do Brasil tenham declinado nas últimas décadas, esta região ainda apresenta os piores indicadores sociais, em relação às demais regiôes do país. Outro aspecto relevante é a presença de fortes padrốes de heterogeneidade na própria região. No presente estudo procurou-se analisar a distribuição espacial dos indicadores socioeconômicos dos municípios da Regiáo Nordeste do Brasil, em especial no que diz respeito às questóes relacionadas à pobreza, renda, habitação e saúde, para os anos de 2000 e 2010. Para tanto, foi utilizada a técnica de análise exploratória de dados espaciais. Entre os resultados obtidos, destacam-se dois: há uma grande disparidade social entre as áreas geográficas da região estudada e há uma associação espacial dos indicadores socioeconômicos dos municípios do Nordeste do Brasil.

PALAVRaS CHAVE | concentração espacial, desigualdade social, economia regional.

ABSTRACT | While poverty and income inequality in Brazil's Northeastern region has declined in recent decades, it still has the worst social indicators in comparison to other areas of the country. Another relevant aspect is the presence of a strong heterogeneity of standards within the region. In this study we analyze the spatial distribution of socio-economic indicators of municipalities in Northeastern Brazil for the years 2000 and 2010. The focus was placed on issues related to poverty, income, housing and health. The technique of exploratory spatial data analysis was used to conduct the research. Among the results, there are two highlights: On the one hand there is a vast social disparity between the geographic areas of the region. On the other hand, there is a spatial association of the socio-economic indicators of the municipalities in Northeastern Brazil.

KEYWORDS | spatial concentration, social inequality, regional economy.

Recibido el 2 de octubre de 2015, aprobado el 2 de julio de 2016.

E-mail: keuler.teixeira@feac.ufal.br 


\section{Introdução}

Atualmente, não há qualquer dúvida em relação ao avanço obtido pelo Brasil nas últimas décadas no que tange à redução da pobreza e desigualdade de renda. Apesar do progresso nestes indicadores, ainda se verifica uma persistência das desigualdades regionais, sobretudo entre a região Nordeste em relação às demais regióes do país. Dentre as cinco macrorregióes brasileiras, o Nordeste ainda é a região que apresenta os piores indicadores sociais.

Além disso, há outra questão relevante que deriva do fato do Brasil possuir dimensóes continentais, onde se encontra numa mesma regiáo um número muito grande de sub-regiôes ou de municípios que exibem realidades completamente distintas, traduzidas, principalmente, por seus diferentes níveis de indicadores socioeconômicos (Pereira \& Porto Junior, 2001).

Desta forma, constata-se também, do ponto de vista espacial, fortes padróes de heterogeneidade nas próprias regiōes, especialmente na região Nordeste. Tal desigualdade intra-regional no Nordeste brasileiro é retrato de uma forte concentração dos investimentos públicos nos estados da Bahia, Ceará e Pernambuco que possuem as principais bases produtivas da região. Observa-se que nas capitais desses estados citados, Salvador, Fortaleza e Recife, respectivamente, encontram-se aproximadamente 20 milhóes de pessoas e 90\% do PIB regional (Araújo, 2008).

O reflexo desta heterogeneidade faz com que os diferentes instrumentos de políticas públicas tenham efeitos distintos de acordo com os territórios sob os quais incidem. Portanto, a compreensão dos motivos pelos quais diferentes localidades, embora situadas relativamente próximas umas das outras, apresentem acentuadas diferenças em relação ao seu grau de desenvolvimento econômico, pode contribuir para fundamentação de políticas públicas direcionadas para a reduçáo dessas desigualdades socioeconômicas.

Diante desse contexto, o debate em torno da temática do desenvolvimento passou a incorporar em suas discussóes, aspectos ligados à relação entre o desenvolvimento de determinadas regióes ou municípios nas relaçóes de vizinhança com outras regióes ou municípios.

Ademais, as pesquisas que se destinam a identificar diferentes padrôes de desenvolvimento entre localidades de uma região não devem negligenciar o papel desempenhado pela dimensão espacial, tendo em vista a importância de complementariedades espaciais entre as unidades de análise. Importância esta que tende a ser maior quanto mais desagregado for o objeto de estudo, como, por exemplo, municípios de um mesmo estado ou região.

Portanto, a questão central deste estudo é analisar a configuração espacial dos indicadores socioeconômico dos municípios nordestinos, de modo a identificar os possíveis padrôes de concentração ou dispersão destes indicadores entre os municípios analisados. De maneira específica, este estudo busca apresentar, por meio de mapas e do coeficiente de correlação espacial, evidências empíricas que possibilitem delinear uma configuração espacial por meio da formação de clusters, principalmente no que se refere às questóes associadas à pobreza, renda, habitação e saúde entre os municípios nordestinos nos anos de 2000 e 2010. Em outras palavras, pretende-se 
observar, especificamente onde estão distribuídos na região Nordeste os agrupamentos de municípios com os melhores e piores desempenhos dos indicadores assinalados anteriormente. Para tanto, foi realizada uma análise exploratória de padróes do comportamento dos indicadores socioeconômicos dos municípios do Nordeste brasileiro, com base em técnicas de Análise Estatística Descritiva Espacial (AEDE).

Além desta introdução, o presente trabalho está distribuído da seguinte forma: na primeira seção é apresentada uma breve revisão de literatura sobre o processo de desenvolvimento da região Nordeste, além de apresentar uma rápida contextualização das desigualdades na referida região. Na seção seguinte, é exposto o procedimento metodológico que será utilizado. Na terceira seção são exibidos os resultados encontrados neste estudo e, por fim, na última seção são apresentadas as conclusôes do trabalho.

\section{Um breve resgate histórico do desenvolvimento do Nordeste}

Os anos 50, no Brasil, foram caracterizados, sobretudo, pela consolidação do debate ideológico sobre o "desenvolvimentismo" que possuía fortes influências da Escola Cepalina. Para esta corrente ideológica, entendia-se que a proposta para superação do subdesenvolvimento seria por meio de um processo de industrializaçáo planejada e guiada pelo Estado. Observa-se ainda que, a economia nordestina, nesse período, exibia um fraco dinamismo em sua base produtiva, que era alicerçada, principalmente, pelo setor produtivo primário-exportado, que por sua vez estava em decadência e náo seria mais capaz de continuar proporcionando o desenvolvimento econômico da região, conforme havia sido diagnosticado pelo relatório apresentado pelo Grupo de Trabalho para o Desenvolvimento do Nordeste (GTDN). Portanto, conforme o referido relatório, a implantação da industrialização era indispensável para superação das dificuldades geradas pela base agroexportadora nordestina (Teixeira \& Pequeno, 2009).

Diante desse cenário, as principais propostas do relatório do GTDN para a Região Nordeste consideravam açóes específicas com objetivo de modificar a realidade, especialmente na área do semi-árido, na Zona da Mata, no Vale do São Francisco, por meio de um Projeto de Irrigação e com a instalação de um "Centro Autônomo Manufatureiro" que estimularia a industrialização de toda a região. Desta maneira, intensificou-se os investimentos, sobretudo nas indústrias de base, dando importância à produção siderúrgica, tais como ferro, aço e indústrias mecânicas, além das atividades industriais que aproveitassem as matérias-primas regionais, isto é, relacionadas à base regional de recursos (Teixeira \& Pequeno, 2009). Segundo Gumiero (2014), nesse período as questóes no âmbito social, como melhoria na qualidade de vida e inclusão social da população, surgiriam como uma consequência de uma combinação bem articulada de políticas econômicas do Estado.

A partir da década 60 , observa-se uma rápida expansão das atividades industriais no Nordeste, estimulada pela política de incentivos fiscais e financeiros. Segundo Araújo (2000) as indústrias denominadas de "dinâmicas" foram aquelas que mais receberam os subsídios, dentre elas pode-se destacar a indústria química, metalúrgica, de minerais não metálicos, de material elétrico, de comunicaçóes e de papelão, 
totalizando aproximadamente $70 \%$ do total de investimentos realizados na regiáo, enquanto que as indústrias tradicionais ligadas aos principais segmentos da regiáo, tais como, têxtil, alimentos, vestuário e calçados, somaram menos do que 30\% destes recursos. Como consequência disso, tem-se uma transformação na estrutura da produção industrial nordestina, tendo em vista que o crescimento foi comandado pelos setores industriais menos tradicionais da regiáo Nordeste.

O crescimento industrial do Nordeste, entre os anos 50 e 60, de acordo autora citada acima, é marcado pela dependência. Observa-se que essa dependência esteve presente, principalmente em relação aos recursos que fomentaram a industrialização da regiáo, pois, a principal massa dos recursos dos impostos utilizados para financiar a industrialização na região era oriunda da região Sudeste, uma vez que esta região concentrava a maior parte das empresas do país, enquanto que somente $26 \%$ total dos recursos eram de origem nordestina. Verifica-se também uma relação de dependência no que se refere o destino da produção, pois os mercados extra-regionais configuravam-se como os principais destinos da produção nordestina. A regiáo Nordeste também exibia uma posição de dependência com relação à origem dos insumos utilizados, pois $48 \%$ dos destes insumos eram adquiridos fora da regiáo. E, por último ressalta-se também a dependência no que se refere à compra de equipamentos, novamente o Sudeste representava o principal fornecedor de bens de capital para região Nordeste.

A década de 1970 caracteriza-se pelo crescimento das atividades industriais e urbanas. Nesse período observa-se também a consolidaçáo do perfil do setor produtivo nordestino, uma vez que regiáo passa a destacar-se na produçáo de bens intermediários e de bens de consumo não-duráveis. Portanto, o Nordeste torna-se um importante fornecedor de insumos para a transformação final que estava concentrada na região Sudeste (Teixeira \& Pequeno, 2009).

Já nos anos 80, em função do aumento das taxas de juros pelos Estados Unidos, posteriormente ao segundo choque do petróleo, tem-se uma instabilidade no desempenho da economia nacional. De acordo com Teixeira e Pequeno (2009), com o objetivo de enfrentar a crise econômica foram elaborados um conjunto de medidas econômicas que visavam estimular as exportaçóes da produção nacional, uma vez que o comércio internacional passava a ser visto como uma importante oportunidade para elevar a produtividade e promover o crescimento econômico. Embora, tendo declinado menos que a produção de outras regióes (especialmente, as da regiáo Sudeste), a produção nordestina não divergiu do padrão nacional, além de elevar também sua participação no mercado externo (Araújo, 2002).

Um conjunto de transformaçóes ligadas ao processo de globalização marcaram os anos 90, como a rápida abertura econômica, aumento da competitividade, a busca pela estabilidade econômica e menor participação do Estado. Essas transformaçôes afetaram o processo de desenvolvimento regional brasileiro gerando efeitos significativos sobre o tecido industrial existente, especificamente sobre a distribuição geográfica das atividades econômicas. Segundo Caldas e Lima (2008), em função do processo de modernização e redução tarifária, observou-se, nesse período, uma menor diversificação da indústria brasileira. Além disso, algumas áreas do Nordeste, sobretudo, as capitais e regióes metropolitanas da referida região, 
atraíram investimentos industriais, revelando-se mais favoráveis ao surgimento de aglomerados produtivos.

De acordo com Lima e Lima (2008), apesar da melhora no padrão tecnológico, a estrutura industrial nordestina, não apresentou expressivas mudanças, uma vez que, no final da década de noventa, o setor produtivo da regiáo continuava fortemente concentrado, tanto pelo lado do emprego, em dois grandes segmentos tradicionais (indústria de produtos alimentícios, bebidas e álcool etílico; indústria têxtil do vestuário e artefatos de tecidos), quanto pelo lado locacional, uma vez que se concentrava, principalmente, em três Estados (Bahia, Ceará e Pernambuco), sobretudo em suas respectivas regióes metropolitanas.

O Brasil entra no século xxi, diante desse novo contexto político e econômico, com objetivo de construir indicadores fiscais mais consistentes, controlar a inflaçáo e desejando tornar-se mais competitivo internacionalmente. Observa-se que, a atual região Nordeste não é mais a mesma daquela regiáo do final dos anos 50 . Desde o momento em que as diretrizes básicas da política de desenvolvimento para região foram definidas pelo GTDN, o processo de construção do espaço nordestino o levaram, ao longo desses quase 60 anos, a um grande mosaico, dividido em torno de sub-regióes desenvolvidas e outras estagnadas (Teixeira \& Pequeno, 2009).

Para Pereira (2015), os anos 2000 são caracterizados, sobretudo a partir do governo Lula (2003-2010), pela retomada do papel do Estado em promover o crescimento econômico no país sob a bandeira do desenvolvimento socioeconômico. Gumiero (2014) destaca que as políticas sociais foram tratadas, anteriormente, como reflexo do crescimento econômico, enquanto que as políticas sociais no governo Lula foram abordadas como ponto central desse novo estímulo de desenvolvimento orquestrado pelo Estado. Observa-se, nesse período, um conjunto de políticas que pretendia superar o subdesenvolvimento, em que reunia medidas voltadas à inclusão social e distribuição de renda aliada às políticas direcionadas ao crescimento econômico. Ainda para o mesmo autor, esse modelo de políticas públicas traduzido tanto pela estabilidade no mercado interno quanto pela inclusão social está no núcleo dos debates teóricos que discutem sobre "novo desenvolvimentismo".

Especialmente, a partir do ano de 2005, conforme Pereira (2015), verifica-se uma significativa retomada nos investimentos públicos com ênfase em infraestrutura de petróleo e gás, energia hidroelétrica e construção civil. Destaca-se também, os investimentos públicos em programas e projetos, via Banco Nacional de Desenvolvimento Econômico e Social (BNDES), que foram direcionados à infraestrutura e produção industrial, onde as maiores parcelas desses recursos foram destinadas aos estados nordestinos. Dentre esses projetos, pode-se enfatizar a Transposição do Rio São Francisco, Complexos Industriais e Portuários no Ceará e instalação de estaleiros e refinaria da Petrobrás, além de planos de montagem de siderúrgica, em Pernambuco. Essa dinâmica é seguida também pela atração de setores industriais, principalmente da indústria de transformaçáo, tais como os setores calçadista, de alimentos e de bebidas, além da construção civil por meio dos programas "Minha Casa, Minha Vida", Aceleração do Crescimento (PAC), dentre outros. Essa atração deu-se, em funçâo de um conjunto de isençôes fiscais por parte dos governos federal e estaduais e oferta de mão de obra mais barata em relaçáo a outras regióes do país. 
Para Araújo (2014), todas essas medidas proporcionaram um maior dinamismo do mercado de trabalho por meio da criaçáo de empregos formais, além do aumento da movimentação dos serviços, ampliando o crédito e estimulando o consumo, verifica-se que ao longo dos anos 2000, a região Nordeste, juntamente com a região Norte lideram a taxa de crescimento do consumo. Ainda conforme a referida autora, entre os anos de 2003 e 2010, a regiáo Nordeste apresenta uma taxa de crescimento superior à média nacional entre o período de 2004 e 2010.

Além dos avanços vistos acima como ampliação do emprego, diminuição da informalidade, recomposição do rendimento e crescimento do Produto Interno Bruto (PIB), observa-se também algumas medidas com caráter mais focalizado e compensatório, de transferência de renda às famílias que se encontram em condição de "extrema pobreza", como por exemplo, o Programa Bolsa Família (pBF) que ampliou a capacidade de consumo de segmentos da sociedade menos favorecidos (Pereira, 2015). Para Araújo (2014) esse programa tem impactado diretamente as famílias nas condições de vida dessa parcela da população, mas também viabilizou uma maior dinamização econômica e territorial no interior do Nordeste estimulando o comércio e gerando nos pequenos municípios um movimento virtuoso de crescimento da economia local.

\section{A desigualdade intra-regional no Nordeste no período 2000 e 2010}

Conforme Araújo (2014), o Nordeste ainda sofre com uma tabela permanente e contínuo de desigualdade regional traduzido pelos seus baixos Índices de Desenvolvimento Humano (IDH) e elevados indicadores de analfabetismo, mortalidade infantil e pobreza.

O crescimento econômico recente não foi suficiente para alterar na mesma velocidade as condiçóes de vida de milhares de pessoas que ainda permanecem atingidas pela exclusão e pobreza, especialmente nas regióes metropolitanas e no sertão semiárido. Para além disso, observa-se também que a distribuição de renda, de terras e de oportunidades continua desigual no Nordeste, ao mesmo tempo que se verifica ainda na região uma forte concentração espacial da indústria e das atividades econômicas de destaque (Pereira Junior, 2012).

Portanto, é nessa circunstância que se insere a regiáo Nordeste ao longo dos últimos anos, onde surgiram novos "vetores" de expansão econômica, acompanhado, porém de taxas desigualdades sociais maiores que a média nacional. Destaca-se, também, que as desigualdades históricas permanecem evidentes na própria região, do litoral ao sertáo semiárido. Deste modo, constata-se que a configuração socioespacial do Nordeste tem sido construída pela combinação de crescimento econômico, desigualdade social e concentração de atividades dinâmicas em determinadas faixas da regiâo (Pereira, 2015). Desta forma, conforme Oliveira (1981), na regiáo Nordeste constata-se a presença de "arquipélagos" de prosperidade, lado a lado com a pobreza. Observa-se, portanto, uma região com centros de dinamismo acompanhados, simultaneamente, de focos de estagnação (Teixeira e Pequeno, 2009).

Essa desigualdade intra-regional no Nordeste, deriva das diferentes bases produtivas de cada território e da maneira pela qual as localidades se integram ao mercado 
doméstico e externo. É notório, que nos últimos anos, ocorreu uma acentuada migração do Centro-Sul em direção a Região Nordeste de diferentes indústrias, especialmente as que empregam mão-de-obra de forma intensiva, atraídas pelos salários menores, fraca ou inexistente força de movimentos sindicais e, especialmente, pelos incentivos fiscais oferecidos pelos Governos locais. Segundo Araújo (2008), tais desigualdades devem-se, principalmente, em razão da forte concentração de investimentos públicos nos estados da Bahia, Ceará e Pernambuco que representam na região as estruturas produtivas mais importantes. Dessa maneira, esse contexto se reflete na repartição do Produto Interno Bruto (РІв) entre os estados nordestinos.

Assim, a tabela 1 apresenta a participação do PIв de cada um dos nove estados nordestinos no PIB regional e também apresenta a participação do PIB de cada macrorregião brasileira no PIB nacional para os anos de 2000 e 2010.

Constata-se que houve, entre os anos analisados, uma queda na participação do pIв dos estados da Bahia e Ceará, e dentre os estados que cresceram o estado de Pernambuco foi o que apresentou o menor percentual. Entretanto, em 2010, os três estados citados, anteriormente, mantinham-se ainda como aqueles que possuíam as maiores participaçóes sobre o PIB da região Nordeste, com destaque para a economia baiana que se apresentou muito superior aos demais. Vale destacar que o Ceará, o terceiro estado em termos de participaçáo sobre o PIB regional, possuía quase o dobro da participação do Maranhão que ocupava a quarta posição naquele ano. Enquanto que, Piauí, Sergipe e Alagoas tinham as menores participaçóes sobre o PIB regional, sendo que, em 2010, a participação do PIB do Sergipe sobre o PIB da região Nordeste era aproximadamente seis vezes menor que a participaçáo do PIB da Bahia sobre a mesma regiáo.

Outro aspecto que chama atenção na tabela 1 é a estrutura da distribuição das participaçóes dos PIB's das macrorregióes brasileiras sobre o PIB nacional. Verifica-se que tal estrutura não sofreu profundas transformações para o período analisado, em que a regiāo Sudeste continuou com uma participação relativa acima dos 50\%, enquanto que a região Nordeste não ultrapassou os 14\%. Destaca-se, também, que, apesar de ter sido verificado um crescimento da participação do PIB nordestino sobre о рів brasileiro, esse crescimento foi inferior ao crescimento obtido pelas regiốes Norte e Centro-Oeste, conforme tabela 1 abaixo.

A seguir, são apresentados o percentual de pessoas pobres ${ }^{1}$ e o índice de Gini para os estados do Nordeste e para regióes brasileiras para os anos de 2000 e 2010. Por meio da tabela 2, observa-se uma significativa redução entre o período analisado para todos os estados nordestinos, corroborando com o fato de que as políticas adotadas para redução da pobreza nesse período tiveram seus efeitos. Porém, vale frisar que mesmo com essa redução o Nordeste ainda apresenta taxa de pobreza mais elevada do país, acima da média nacional. Os dados enfatizam o histórico de desigualdades da região, quando se comparam com outras regióes ou com a média brasileira.

1 Considera-se aqui a proporçáo dos indivíduos com renda domiciliar per capita igual ou inferior a $\mathrm{R} \$ 140,00$ mensais, em valores em reais $(\mathrm{R} \$)$ para agosto de 2010. 
TAbela I | Participação do PIB (\%), por Regióes e Estados do Nordeste (2000 e 2010)

\begin{tabular}{|c|c|c|c|}
\hline ESTADOS/NORDESTE & 2000 & 2010 & VARIAÇÃO \\
\hline Alagoas & 5.29 & 4.84 & -8.48 \\
\hline Bahia & 31.69 & 30.41 & -4.02 \\
\hline Ceará & 15.40 & 15.34 & -0.35 \\
\hline Maranhão & 8.11 & 8.92 & 9.94 \\
\hline Paraíba & 6.36 & 6.29 & -1.02 \\
\hline Pernambuco & 18.36 & 18.76 & 2.15 \\
\hline Piauí & 4.13 & 4.35 & 5.27 \\
\hline Rio Grande do Norte & 6.21 & 6.37 & 2.59 \\
\hline Sergipe & 4.45 & 4.72 & 5.87 \\
\hline REGIÓES/BRASIL & 2000 & 2010 & VARIAÇÃO \\
\hline Região Nordeste & 12.45 & 13.46 & 8.14 \\
\hline Região Centro-oeste & 8.39 & 9.30 & 10.89 \\
\hline Região Norte & 4.38 & 5.34 & 21.93 \\
\hline Região Sul & 16.47 & 16.51 & 0.21 \\
\hline Região Sudeste & 58.31 & 55.39 & -5.01 \\
\hline
\end{tabular}

FONTE ELABORAÇÃO PRÓPRIA A PARTIR DOS DADOS DO INSTITUTO DE PESQUISA ECONÔMICA APLICADA - IPEA (2OI4)

Com relação ao índice de Gini, também houve uma melhora desse indicador para todos os estados do Nordeste, em conformidade com a melhora dos indicadores sociais do país na última década. No entanto, como no caso anterior, essa melhora náo foi suficiente para acompanhar a média nacional, revelando que os benefícios adquiridos não foram absorvidos de forma igualitária por todas as regióes. Dentro desse contexto, a região Sul, além de ter exibidos os menores níveis do índice de Gini, também apresentou a maior taxa de redução do referido indicador. Enquanto que a regiáo Nordeste, embora tenha registrado uma reduçáo na concentração de renda no período em questão, continuou, em 2010, ocupando o posto de regiáo mais desigual do país, conforme tabela 2.

Teague e Wilson (1995) entendem que, a persistência das desigualdades sociais configura-se como um forte indicador da necessidade para elaboração de novas propostas de políticas públicas que minimizem este processo. Nesse contexto, observa-se que a influência do território tem sido negligenciada no planejamento das políticas públicas. Para Santos (2001) qualquer proposta política que despreze a dinâmica territorial será ineficaz, porque o processo de desigualdade social manifesta-se territorialmente e desprezar tal dinâmica significa ignorar a dimensão espacial dessas disparidades presentes nas cidades brasileiras. 
TABela 2 Evoluçáo da pobreza e desigualdades, por Regióes e Estados do Nordeste (2000 e 2010)

\begin{tabular}{|c|c|c|c|c|c|c|}
\hline $\begin{array}{c}\text { REGIÓES E } \\
\text { ESTADOS DO NE }\end{array}$ & $\begin{array}{l}\text { PESSOAS } \\
\text { POBRES, } \\
2000(\%)\end{array}$ & $\begin{array}{l}\text { PESSOAS } \\
\text { POBRES, } \\
\text { 2OIO (\%) }\end{array}$ & $\begin{array}{l}\text { VARIAÇÃo } \\
(\%)\end{array}$ & $\begin{array}{c}\text { ÍNDICE } \\
\text { DE GINI } \\
(2000)\end{array}$ & $\begin{array}{l}\text { ÍNDICE } \\
\text { DE GINI } \\
(2010)\end{array}$ & $\begin{array}{l}\text { VARIAÇÃo } \\
(\%)\end{array}$ \\
\hline Alagoas & 56.8 & 34.29 & -39.63 & 0.68 & 0.63 & -7.35 \\
\hline Bahia & 49.72 & 28.72 & -42.24 & 0.66 & 0.62 & -6.06 \\
\hline Ceará & 51.75 & 30.32 & -41.41 & 0.67 & 0.61 & -8.96 \\
\hline Maranhão & 62.78 & 39.53 & -37.03 & 0.65 & 0.62 & -4.62 \\
\hline Paraíba & 49.61 & 28.93 & -41.69 & 0.63 & 0.61 & -3.17 \\
\hline Pernambuco & 45.27 & 27.17 & -39.98 & 0.66 & 0.62 & -6.06 \\
\hline Piauí & 57.28 & 34.11 & -40.45 & 0.65 & 0.61 & -6.15 \\
\hline Rio Grande do Norte & 44.89 & 23.79 & -47.00 & 0.64 & 0.6 & -6.25 \\
\hline Sergipe & 48.84 & 27.89 & -42.90 & 0.65 & 0.62 & -4.62 \\
\hline \multicolumn{7}{|l|}{ REGIÓES/BRASIL } \\
\hline Região Nordeste & 51.88 & 30.53 & -41.16 & 0.65 & 0.62 & -5.94 \\
\hline Região Centro-oeste & 19.52 & 8.24 & -57.79 & 0.62 & 0.57 & -7.29 \\
\hline Região Norte & 40.87 & 25.75 & -37.01 & 0.63 & 0.61 & -3.38 \\
\hline Região Sul & 15.75 & 5.49 & -65.12 & 0.58 & 0.52 & -10.34 \\
\hline Regiāo Sudeste & 17.71 & 8.10 & -54.28 & 0.60 & 0.57 & -5.02 \\
\hline BRASIL & 35.16 & 19.88 & -43.45 & 0.63 & 0.59 & -5.79 \\
\hline
\end{tabular}

Para Theis e Galvão (2012), as atitudes desprendidas em prol dos indivíduos podem ser direcionadas e estar mais relacionadas à localidade onde os problemas se apresentam. Caso contrário, tem-se uma dispersão desses esforços, tornando a aplicação dessas medidas ineficiente, além de além de torna-la ineficaz para alcançar as respostas desejadas. $\mathrm{O}$ espaço constitui um elemento importante para expandir a eficiência de políticas de desenvolvimento na sua função de reduzir desigualdades e equiparar as condiçôes básicas dos cidadãos. Desta forma, desmerecer a importância da dimensão espacial da realidade social dificultará à sua compreensão.

Considerar tanto uma abordagem conceitual quanto territorial, por meio de indicadores socioespaciais, auxilia na efetividade de políticas públicas, pois permite que essas vertentes possam ir além da caraterização de carências, revelando também as possíveis potencialidades locais que serão importantes para a redução das desigualdades sociais (Genovez, 2002). Portanto, a utilização dos Sistemas de Informaçóes Geográficas (SIG) aliados às técnicas de Análise Espacial de Dados Geográficos (AE) representa uma ferramenta importante para a definição de políticas públicas, pois permite analisar e integrar diferentes dados numa mesma base territorial. As próximas seçóes deste trabalho investigam a existência de dependência espacial entre os indicadores socioeconômicos dos municípios da região Nordeste. 


\section{Aspectos metodológicos e base de dados}

Neste trabalho recorreu-se a técnicas de estatística espacial, por meio da Análise Exploratória de Dados Espaciais (AEDE). A AEDE auxilia a compreensão de fenômenos espaciais por meio de um conjunto de técnicas empregadas para descrever as distribuições espaciais de variáveis, além de apontar padrôes de correlação espacial, podendo também evidenciar a presença de clusters e outliers (Anselin, 1988).

Para capturar a ocorrência de tais associaçóes a referida técnica fornece medidas globais e locais de autocorrelaçáo espacial, podendo ser verificada por meio de testes formais de associação espacial, tais como as estatísticas $I$ de Moran global e o I de Moran local, também conhecido como Indicador Local de Associação Espacial (Local Indicator of Spatial Association - LISA).

A presença de autocorrelação espacial é medida geralmente por meio de estatísticas globais. Neste caso, os dados são analisados de maneira generalizada, avaliando a associação espacial de uma região inteira por meio de um indicador global conhecido por I de Moran Global. Este indicador analisa o nível de interdependência geográfica entre as variáveis de interesse, além de indicar a natureza e o grau de tal relação. O índice $I$ de Moran situa-se entre $-1 \mathrm{a}+1$ e testa a hipótese nula de que há independência espacial ou ausência de autocorrelação espacial $\left(H_{0}: I=0\right)$ contra a hipótese alternativa de que existe uma dependência espacial ou presença de autocorrelação espacial $\left(H_{1}: I \neq 0\right)$.

Portanto, valores do índice próximos à zero ou não significativos apontam para uma independência espacial, isto é, para uma ausência de autocorrelação espacial significativa entre os valores da variável de interesse entre as regióes. Por outro lado, valores positivos e significativos do I de Moran assinalam uma dependência ou autocorrelação espacial positiva. Em outras palavras, o valor da variável de interesse numa determinada regiáo tende a ser similar aos de seus vizinhos. Já os valores negativos e significativos do $I$ de Moran indicam a presença de uma autocorrelação ou dependência espacial negativa, isto é, o valor da variável em questão numa determinada regiáo tende a ser diferente dos valores observados em seus vizinhos.

Formalmente este índice é expresso por:

$$
I=\frac{n}{\sum \sum w_{i j}} \cdot \frac{\sum \sum w_{i j}\left(y_{i}-\bar{y}\right)\left(y_{j}-\bar{y}\right)}{\sum\left(y_{i}-\bar{y}\right)^{2}} \text { (1) }
$$

Onde, $n$ é o número de unidades espaciais ou número de observações, $y_{i}$ e $y_{j}$ são os valores observados da variável dos municípios $i$ e $j, \bar{y}$ é a média do valor observado da variável de interesse de todos os municípios, $w_{i j}$ representa os elementos da matriz de peso espacial que define as relaçóes de vizinhança ${ }^{2}$, isto é, o peso espacial para o par de unidades espaciais $i$ e $j$, medindo o grau de interação entre elas, com $i=1,2, \ldots, n$ e $j=1,2, \ldots, n$.

2 Para a construçáo dos indicadores foi utilizada uma matriz de contiguidade do tipo queen que considera além das fronteiras com extensão maior que zero, os vértices de outras áreas que encontram com a área em estudo e passam a ser consideradas como contíguas, recebem valor um e os demais valores zero. Em geral náo existem regras definidas para a escolha das matrizes de pesos espaciais a serem empregadas de forma mais adequada. 
A indicação de presença de associação espacial global pode demonstrar conformidade com padrôes locais, porém, isso não é absoluto. Alguns casos de ausência de associação espacial global encobrem padróes locais de associação (Almeida, 2012). Os indicadores locais, diferentemente das estatísticas globais, fornecem um valor específico para cada área possibilitando a identificação de agrupamentos com valores similares (clusters) ou dissimilares (outliers) e de regimes espaciais, não observados por meio dos resultados globais.

Para superar tal empecilho e identificar a ocorrência de autocorrelação local, Anselin (1995) propóe uma decomposição em categorias do indicador I de Moran, dado por:

$$
I_{i}=\frac{\left(y_{i}-\bar{y}\right) \sum_{j}^{n} w_{i j}\left(y_{j}-\bar{y}\right)}{\sum_{j}^{n} \frac{\left(y_{i}-\bar{y}\right)^{2}}{n}}=n \cdot \frac{z_{i} \cdot \sum_{j}^{n} w_{i j} z_{j}}{\sum_{j}^{n} z_{j}^{2}}
$$

O n d e $z_{i}=\left(y_{i}-\bar{y}\right)$ e $z_{j}=\left(y_{j}-\bar{y}\right)$ são variáveis padronizadas e a somatória sobre $j$ é tal que somente os valores dos vizinhos $j \in J_{i}$ são incluídos. $O$ conjunto $J_{i}$ abrange os vizinhos da observação $i$.

Portanto, a partir dos resultados gerados pela estatística LISA, pode-se determinar quatro padrōes de autocorrelação espacial, os quais indicam a formação de clusters. Estes padróes são definidos como Alto-Alto (AA) e Baixo-Baixo (вв) que apontam as regióes que apresentam uma associação espacial homogênea, isto é, regiôes com valores altos/baixos da variável de interesse pertencente a uma vizinhança com valores também altos (baixos). Já os padróes Alto-Baixo ( $\mathrm{AB}$ ) e Baixo-Alto (BA) indicam padróes heterogêneos de associação espacial, isto é, localidades com valores altos/baixos da variável em análise localizados numa vizinhança com valores baixos (altos).

Os indicadores socioeconômicos utilizados neste estudo refere-se à proporção dos indivíduos com renda domiciliar per capita igual ou inferior a $\mathrm{R} \$ 140$ mensais, em reais de agosto de 2010, que chamaremos aqui de "percentual de pobres", outro indicador é a renda per capita que é entendida como a razão entre o somatório da renda de todos os indivíduos residentes em domicílios particulares permanentes e número total desses indivíduos (valor em reais de 01/agosto de 2010), além desses, ainda foram utilizados o índice de Gini, o percentual de pessoas em domicílios sem energia elétrica (como uma proxy para infraestrutura domiciliar) e, por fim, a taxa de mortalidade infantil ${ }^{3}$ para os municípios da região Nordeste.

Essas informaçóes sáo referentes aos anos 2000 e 2010 de acordo com dados disponibilizados no Instituto de Programa das Naçóes Unidas para o Desenvolvimento (PNUD). Esse período foi escolhido com base na disponibilidade de dados de forma a possibilitar uma comparação direta com dados entre os anos analisados para todos os municípios ${ }^{4}$.

3 Refere-se ao número de crianças que não deverão sobreviver ao primeiro ano de vida em cada mil crianças nascidas vivas.

4 Vale destacar que no momento desta pesquisa o período escolhido refere-se às informaçôes mais recentes com relação às variáveis analisadas neste estudo, tendo em vista que as mesmas são construídas a partir do Censo Demográfico brasileiro que tem periodicidade decenal. 


\section{Resultados}

A análise espacial possibilita apreender se os indicadores socioeconômicos nos municípios nordestinos acontecem de forma aleatória ou se existem evidências de algum tipo de dependência. A dependência ou autocorrelação espacial é provocada pela interaçáo dos agentes no espaço. Conforme Almeida (2012), um atributo qualquer associado a um determinado município pode sofrer influências significativas de certos fatores advindos de outros municípios que são, geograficamente, vizinhos. É essencial analisar essa tendência de concentração por meio de testes estatísticos de autocorrelaçáo espacial. O primeiro dos testes realizados no presente estudo é o diagrama de dispersão do I de Moran Global para os anos de 2000 e 2010.

Conforme a figura 1, a partir dos dados coletados criou-se um diagrama de espalhamento de Moran, em que o valor do índice I de Moran global para o percentual de pessoas pobres em 2000 foi de 0,445484. Com objetivo de validar este resultado foram realizadas 999 permutaçóes e obteve-se um valor- $p=0,001$. Portanto, pode-se rejeitar a hipótese nula de ausência de autocorrelação espacial entre os municípios nordestinos, ao nível de significância de $1 \%$. E, para o ano de 2010, obteve-se o valor do índice $I$ de Moran de 0.507682 , com um valor-p igual a 0.001 , o que indica que o resultado encontrado foi estatisticamente significante a $1 \%$.

De maneira geral, conclui-se que na regiāo Nordeste existia, para os anos analisados, uma forte indicação de autocorrelação global positiva, ou seja, em média, os municípios com maiores percentuais de pobres eram circundados por municípios na mesma situaçáo, enquanto que os municípios menores percentuais de pobres eram vizinhos de municípios na mesma circunstância.

FIgURA I | I de Moran global para a pobreza do Nordeste em 2000 e 2010

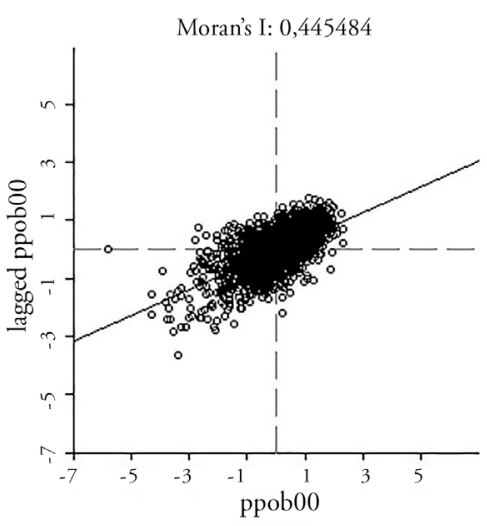

2000

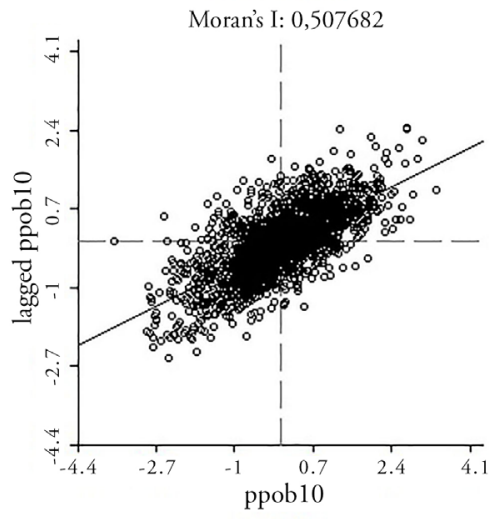

2010

FONTE ELABORAÇÃo PRÓPRIA A PARTIR DOS DADOS DO PROGRAMA DAS NAÇÕES UNIDAS PARA O DESENVOLVIMENTO - PNUD (2014) 
O detalhamento exposto com o diagrama de dispersão não permite apontar geograficamente os clusters de municípios com índices semelhantes. Portanto, é necessário recorrer ao Indicador Local de Associação Espacial (LISA), permitindo a classificação dos municípios da região Nordeste em quatro categoriais como visto na seçáo 2 .

Assim, de acordo com a figura 2, por meio do Indicador Local de Associação Espacial (LISA), observa-se que, para o ano de 2000, havia uma predominância de municípios distribuídos entre os estados do Maranhão e Piauí concentrados no cluster Alto-Alto, ou seja, municípios que apresentavam altos percentuais de pobreza e que são vizinhos aos municípios com índices similares. No estado do Maranhão essa concentração ocorria basicamente nos municípios localizados nas mesorregióes Norte e Oeste Maranhense, enquanto que para o estado do Piauí, municípios deste agrupamento concentravam-se, principalmente, nas mesorregióes Norte e Sudeste do referido estado.

FIgURA 2 | Clusters da pobreza do Nordeste em 2000 e 2010

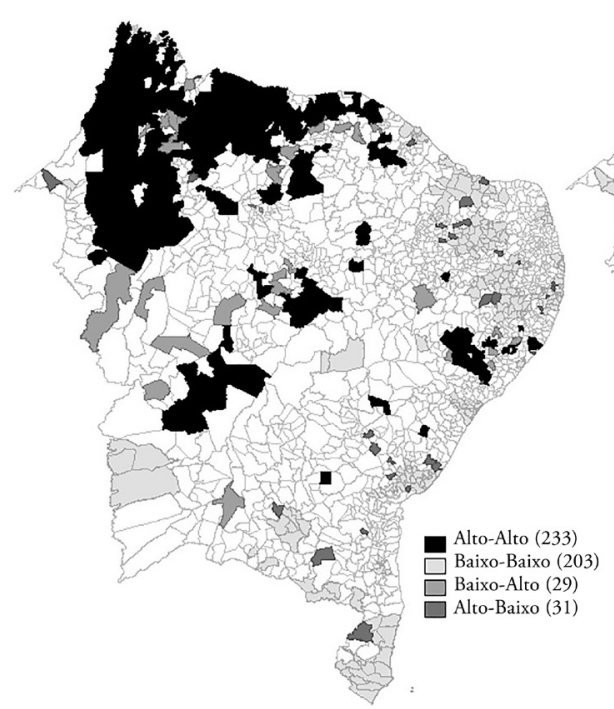

2000

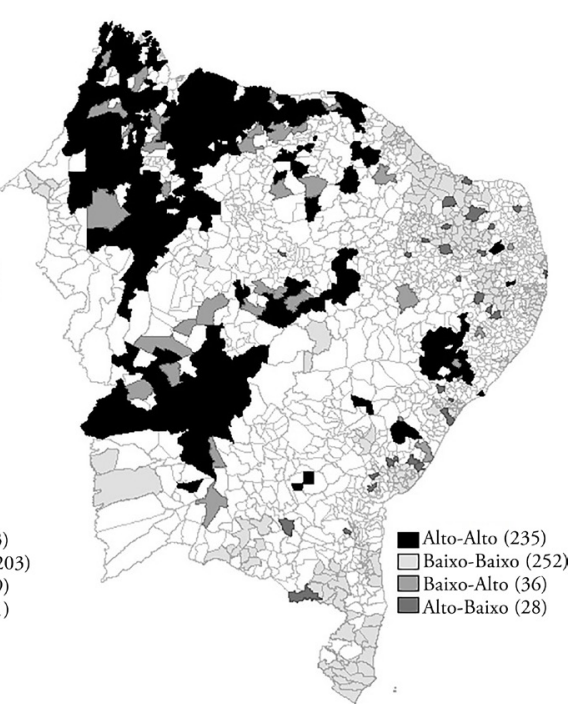

2010

FONTE ELABORAÇÃo PRÓPRIA A PARTIR DOS DADOS DO PROGRAMA DAS NAÇÓES UNIDAS PARA O DESENVOLVIMENTO - PNUD (20I4)

Verifica-se que ao se passar uma década os estados do Maranhão e Piauí concentravam, novamente, os maiores números de municípios pertencentes aos clusters Alto-Alto. Deve-se destacar que, ao longo desse período, houve no Estado da Bahia uma expansão do número de municípios inseridos no cluster Alto-Alto, concentrados basicamente na mesorregião do Vale do São Francisco e Extremo Oeste baiano. Entretanto, é justamente no mesmo estado que se concentravam o maior número de municípios localizados no cluster Baixo-Baixo quando comprado aos demais estados nordestinos, isto é, municípios que apresentavam baixos índices 
de pobreza e que são vizinhos aos municípios com indicadores semelhantes. Os municípios pertencentes a este agrupamento estavam concentrados, sobretudo nas mesorregiốes Metropolitana, Sul e Centro Sul do estado. Esse aspecto demonstra a forte disparidade entre os próprios municípios do estado da Bahia.

Dentro desse contexto, destacam-se também os estados do Rio Grande do Norte e Pernambuco. Para o estado do Rio Grande do Norte, as mesorregióes Oeste e Central concentravam o maior número de municípios que possuíam baixos índices de pobreza e que possuíam vizinhos com características similares. Já no estado do Pernambuco, os municípios pertencentes ao cluster Baixo-Baixo, estavam localizados, principalmente nas mesorregióes Metropolitana Agreste e Zona da Mata. De maneira geral, observa-se uma forte concentração da pobreza, principalmente, na sub-regiáo nordestina conhecida como Meio Norte (área que se estende do Maranhão ao Oeste do Piauí). Por outro lado, a faixa litorânea da região que se insere a sub-região da Mata Atlântica, e parte do litoral cearense que está inserido na sub-região Sertão, verifica-se uma maior aglutinação de municípios com baixos percentuais de pobreza.

\section{FIGURA 3 | I de Moran global para a renda per capita do Nordeste em 2000 e 2010}
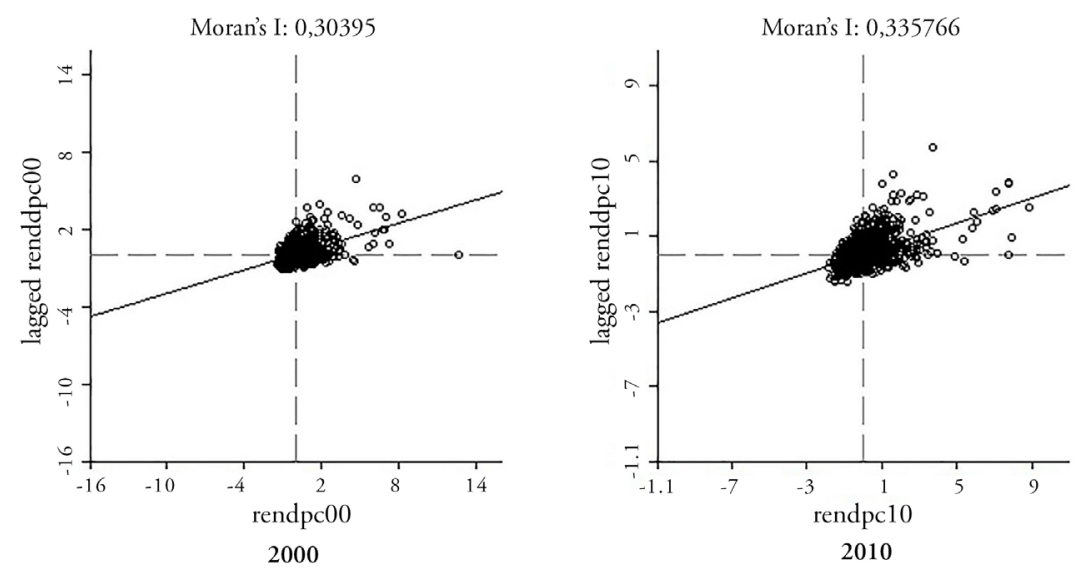

FONTE ELABORAÇÃO PRÓPRIA A PARTIR DOS DADOS DO PROGRAMA DAS NAÇÓES UNIDAS PARA O DESENVOLVIMENTO - PNUD (2OI 4 )

Na figura 3, analisa-se o diagrama de dispersão de Moran para indicador renda per capita que tem por base demonstrar as desigualdades entre as diferentes rendas da região. Os resultados gerados, para o ano de 2000, indicam um valor do índice $I$ de Moran global igual a 0.30395 , com um valor-p igual a 0.001 , rejeitando, portanto, a hipótese nula de ausência de autocorrelação espacial entre os municípios nordestinos, ao nível de significância de $1 \%$. Por sua vez, para o ano de 2010 , obteve-se $I$ de Moran igual a 0.335766 e valor-p de 0.001 , novamente constatou-se a presença de uma dependência espacial para os municípios analisado naquele ano. Temos que, em média, os municípios com renda per capita mais alta eram circunvizinhos de 
municípios na mesma situação, enquanto que os municípios que apresentam renda per capita menor eram vizinhos de municípios na mesma circunstância.

$\mathrm{Na}$ figura 4, por meio do Indicador LISA observam-se geograficamente os clusters de municípios com valores similares, para o ano de 2000, tinha-se 113 municípios no cluster Alto-Alto, onde se encontravam distribuídos, predominantemente, entre os estados da Bahia, Rio Grande do Norte e Pernambuco. No estado da Bahia, verificou-se uma concentração desses municípios entre as mesorregióes Metropolitana e Sul do estado, por sua vez, as mesorregióes Central e Leste no Rio Grande do Norte, foram aquelas que apresentaram maior número de municípios no agrupamento Alto-Alto, e por fim, no estado de Pernambuco, tal concentração aconteceu, basicamente, nas mesorregióes Metropolitana e Agreste do estado.

Ainda no mesmo ano, tinha-se uma concentração de 167 municípios no grupo Baixo-Baixo, concentrados, basicamente nos estados do Maranhão e Piauí. Mais especificamente, aquele grupo de municípios com baixo nível de renda per capita $\mathrm{e}$ que possuía vizinhos com indicadores similares estavam distribuídos espacialmente nas mesorregióes Norte e Leste do estado do Maranhão, e Norte e Centro-Norte do estado do Piauí.

FIGURA 4 | Clusters da renda per capita do Nordeste em 2000 e 2010

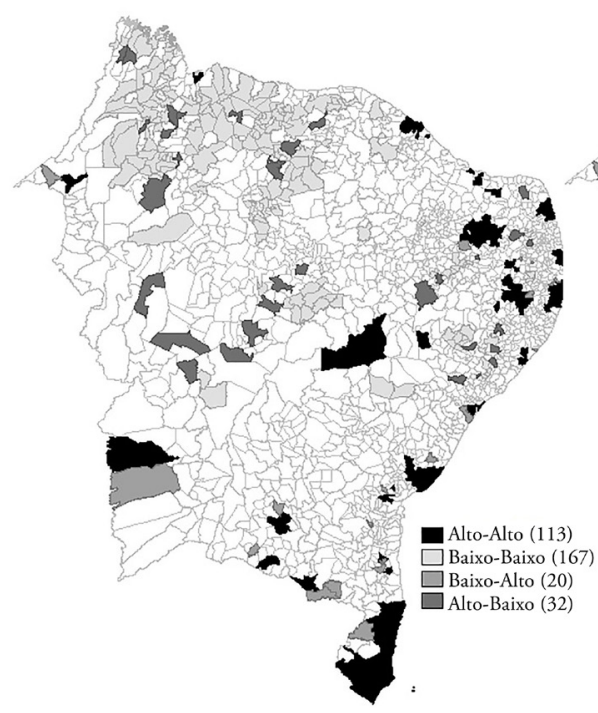

2000

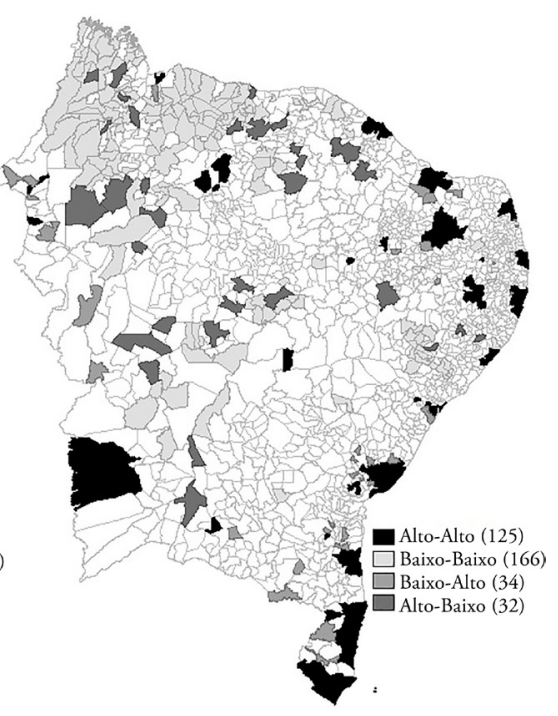

2010

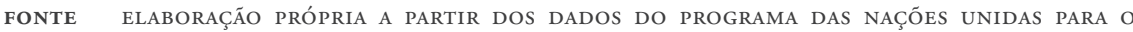
DESENVOLVIMENTO - PNUD (2OI4)

Para o ano de 2010, na figura 4, os municípios inseridos no grupo Alto-Alto, continuavam, em sua grande maioria, concentrados entre os estados da Bahia, Rio Grande do Norte e Pernambuco. Com relação ao cluster Baixo-Baixo para o ano de 2010, verificou-se que não houve mudança na sua configuração espacial, tendo vista 
que, novamente os estados do Maranhão e Piauí mantiveram em seus territórios a maioria de municípios pertencentes a este cluster. Pode-se verificar que, de maneira geral, a maior concentração de municípios nos clusters Alto-Alto, situa-se basicamente na faixa litorânea da regiáo Nordeste que se estende desde do litoral cearense até o Sul da Bahia.

Na figura 5, tem-se o diagrama de dispersão de Moran para o Índice de Gini, em que os valores do índice $I$ de Moran global e valor- $p$ em 2000, foram respectivamente 0.223766 e 0.001 . Para o ano de 2010, o I de Moran para foi de 0.322728 e o valor-p de 0.001 . Portanto, rejeitou-se a hipótese nula de ausência de autocorrelação espacial entre os municípios nordestinos, ao nível de significância de 1\%. Os resultados gerados sinalizam que, em média, os municípios uma maior concentração de renda estavam próximos de municípios na mesma situação, enquanto que os municípios que com uma menor concentração de renda eram vizinhos de municípios na mesma condição.

Figura 5 | I de Moran global para o índice de Gini do Nordeste em 2000 e 2010
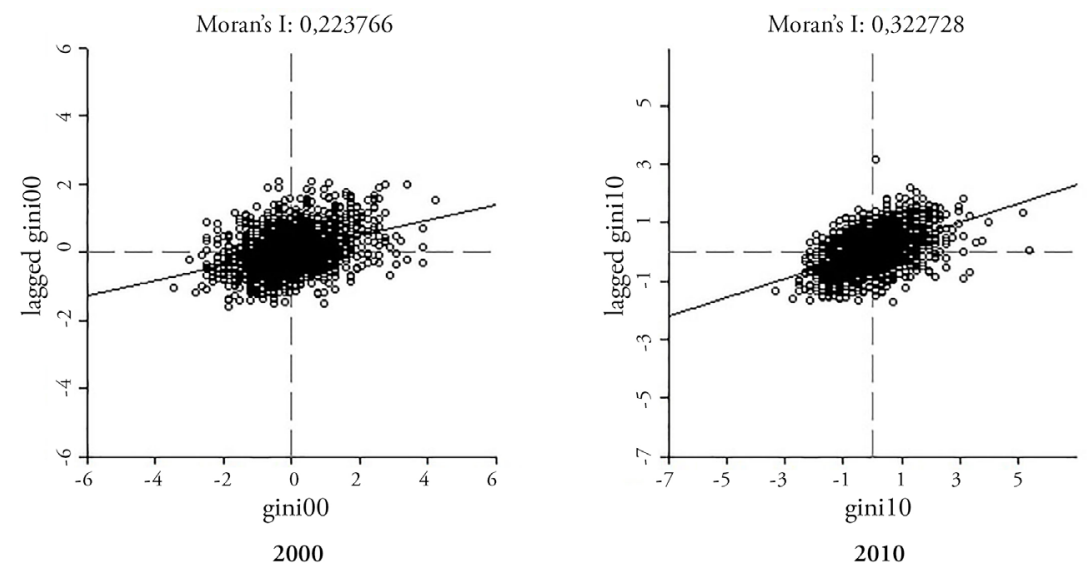

FONTE ELABORAÇÃO PRÓPRIA A PARTIR DOS DADOS DO PROGRAMA DAS NAÇÓES UNIDAS PARA O DESENVOLVIMENTO - PNUD (2OI4)

De acordo com a figura 6, pode-se observar a configuração espacial do índice de Gini. Para o ano de 2000, os municípios com elevadas desigualdade de renda e que possuíam vizinhos com características semelhantes, isto é, cluster Alto-Alto, concentraram-se de forma, predominante, no estado do Ceará, principalmente nas Mesorregióes Noroeste, Sertôes e Sul do estado. Destaca-se também a Bahia, em que os municípios inseridos no cluster Alto-Alto, localizavam-se, basicamente nas mesorregiốes do Vale do São Francisco, Centro Sul e Extremo Oeste baiano. Apesar de possuir uma dimensáo territorial menor, com relaçáo aos estados nordestinos citados acima, o estado de Alagoas, também concentrou um grande número de municípios pertencentes ao agrupamento Alto-Alto, principalmente, na mesorregião do Sertão Alagoano. 

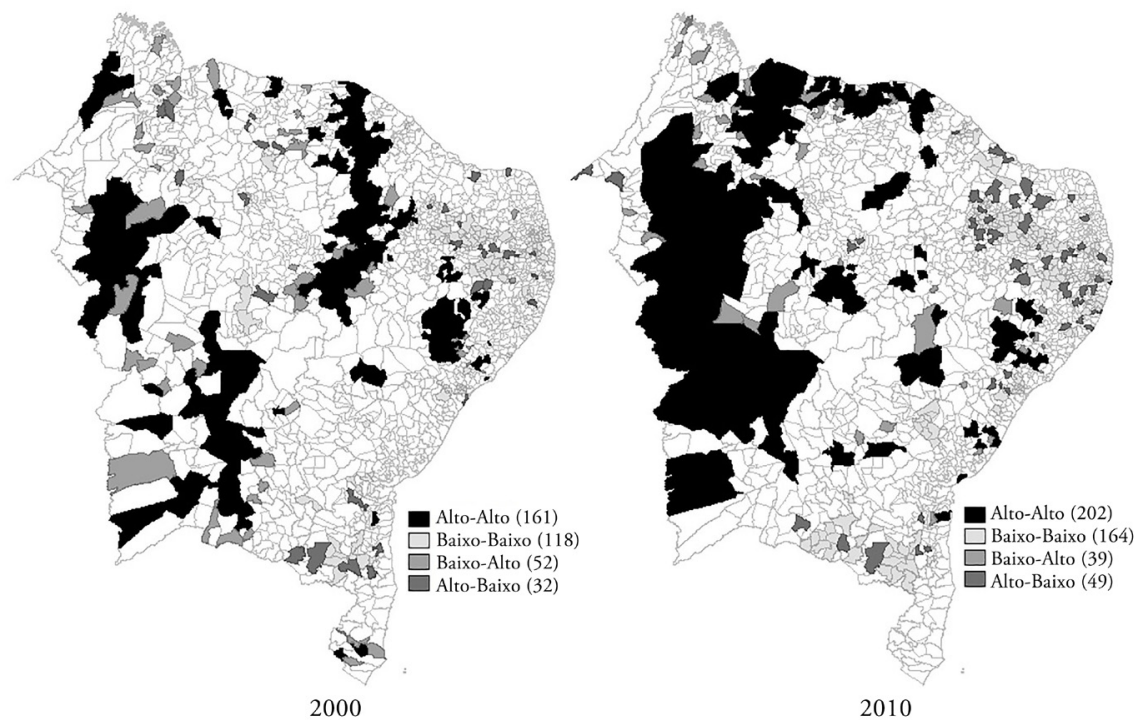

FONTE ELABORAÇÃo PRÓPRIA A PARTIR DOS DADOS DO PROGRAMA DAS NAÇÓES UNIDAS PARA O DESENVOLVIMENTO - PNUD (20I4)

Para o ano de 2010 observa-se uma ampliação do número de munícipios pertencentes ao cluster Alto-Alto e uma nova configuração espacial da concentração de renda na região. Constatou-se no estado Ceará uma forte redução do número de municípios inseridos no cluster Alto-Alto e uma ampliação do número de municípios inserido nesse cluster nos estados do Maranhão, Piauí e Bahia. No Maranhão, esses municípios estavam concentrados, especialmente nas mesorregióes Leste, Norte e Centro do estado. Já no Piauí, as cidades com índice de Gini elevado e que eram vizinhas de localidades com indicadores semelhantes concentravam-se nas mesorregiôes Sudoeste e Sudeste piauiense. E, por último no estado da Bahia, tinham-se, novamente, as mesorregióes do Vale do São Francisco, Extremo Oeste, mas agora com a presença da mesorregiáo do Centro Norte baiano como aquelas que concentravam o maior número de municípios pertencentes ao cluster Alto-Alto.

Com relação ao cluster Baixo-Baixo, para o ano de 2000, isto é, grupo de municípios com índice de Gini baixo que possuíam vizinhos em condiçôes similares, observa-se uma forte concentração desses municípios nos estados da Paraíba, Rio Grande do Norte e Sergipe. Para o estado da Paraíba, os municípios que possuíam baixos índices de Gini e que tinham vizinhos na mesma condição estavam concentrados, principalmente nas mesorregióes Borborema e Sertão paraibano. Já no Rio Grande do Norte, os municípios pertencentes ao cluster Baixo-Baixo, localizavam-se, principalmente na mesorregião Central do estado. No Sergipe, havia uma concentração nos municípios localizados nas mesorregióes Agreste e Leste do estado. Para o ano de 2010, essa composição espacial do índice de Gini na região Nordeste não se 
alterou, tendo novamente os estados analisados acima, como aqueles com o maior número de municípios pertencentes ao agrupamento Baixo-Baixo.

A seguir, analisa-se a dependência espacial dos domicílios sem energia elétrica, conforme a figura 7 a seguir. Para o ano de 2000, o valor do índice I de Moran foi de 0.627869 e com um valor- $p=0.001$, e para o ano de 2010, I de Moran foi de 0.564512 e o valor-p de 0.001 , indicando, portanto, a dependência espacial da variável em questão. A análise do diagrama de dispersão de Moran revela que a maioria dos municípios nordestinos encontrava-se nos quadrantes que representam a existência de autocorrelação espacial positiva. Portanto, os municípios que possuíam um menor número de domicílios atendidos por esse serviço público também possuíam vizinhos na mesma circunstância.

FIgURA 7 | I de Moran global para os domicílios sem energia elétrica do Nordeste em 2000 e 2010
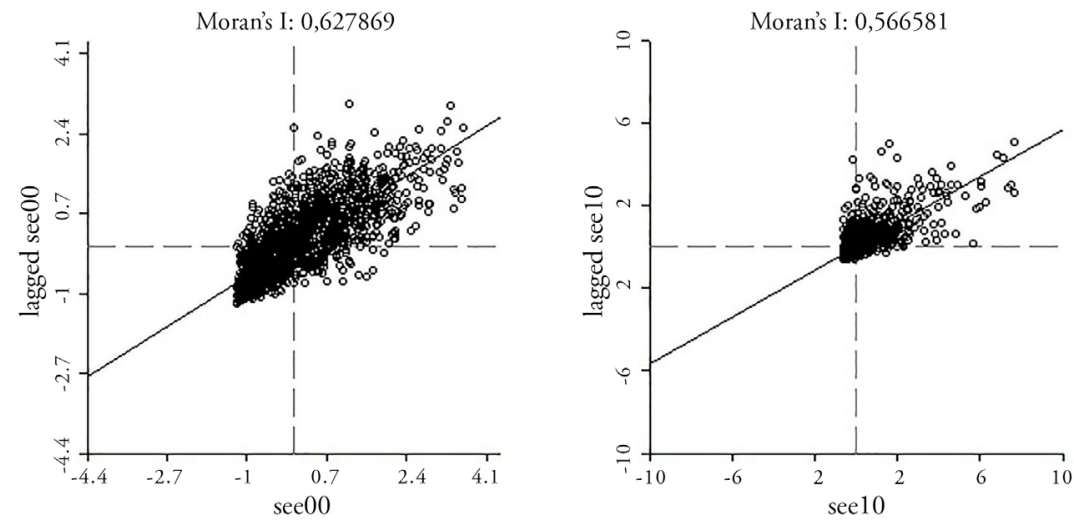

2000

FONTE ELABORAÇÃO PRÓPRIA A PARTIR DOS DADOS DO PROGRAMA DAS NAÇÓES UNIDAS PARA O DESENVOLVIMENTO - PNUD (2OI4)

Para confirmar a análise anterior, recorre-se ao Indicador Local de Associação Espacial (LISA), que irá nos mostrar os clusters de municípios com índices semelhantes. Dentre os índices com significância, encontrou-se uma predominância para a classificação Alto-Alto e Baixo-Baixo. Esse resultado mostra que cidades com alta proporção de acesso à energia estavam circundadas por municípios com as mesmas características, devido à condição de proximidade espacial, conforme figura 8 .

Os municípios que representam geograficamente o cluster Alto-Alto, para os anos 2000 e 2010, situavam-se, principalmente nos Estados Piauí, Bahia e Maranhão, mais especificamente nas mesorregióes Sudeste, Sudoeste e Centro Norte no estado do Piauí, Centro Sul, Nordeste e Extremo Oeste no estado da Bahia, e por último, nas mesorregiôes Norte e Sul do Maranhão. A mesma análise é feita para o ano de 2010, com exceção da saída da mesorregião Norte maranhense e entrada da mesorregião Oeste do Maranhão. Também, houve alternância entre as mesorregióes no Estado da Bahia, com a saída do Centro Sul e entrada da mesorregiấo Sul baiano. 
FIgURA 8 | Clusters dos domicílios sem energia elétrica do Nordeste em 2000 e 2010
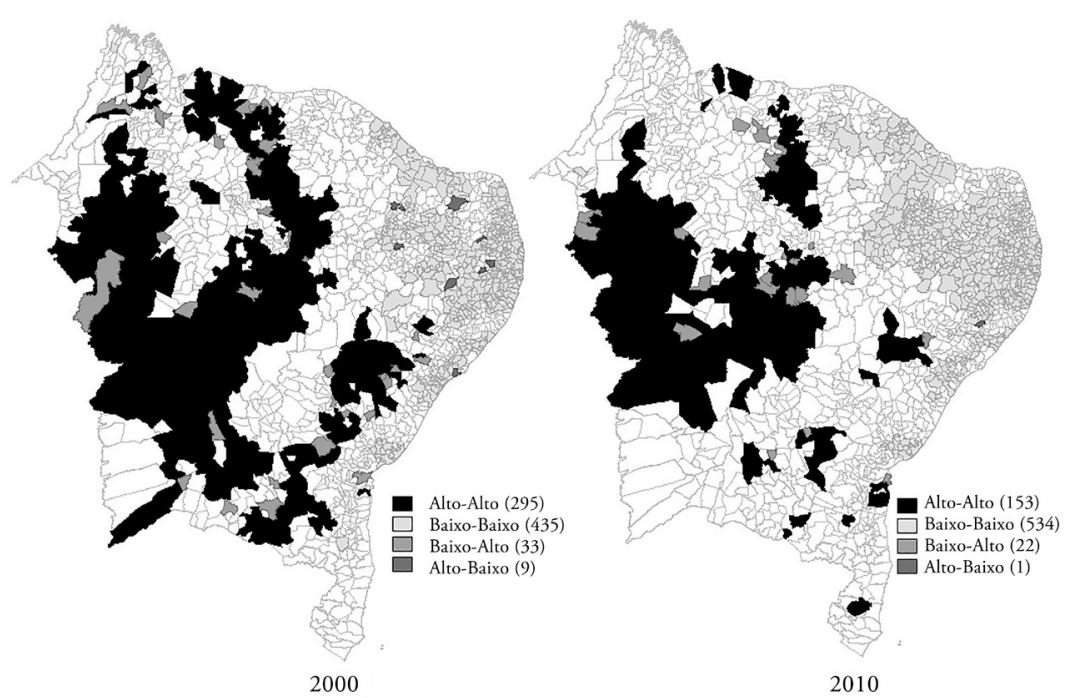

FONTE ELABORAÇão PRÓPRIA A PARTIR DOS DADOS DO PROGRAMA DAS NAÇÓES UNIDAS PARA O DESENVOLVIMENTO - PNUD (2OI4)

Segundo a figura 8, pode-se observar que entre os anos 2000 e 2010, houve um aumento no número de municípios inseridos no cluster Baixo-Baixo, ampliando-se de 435 para 534 municípios que possuíam baixos percentuais de domicílios sem energia elétrica e que possuíam vizinhos com características similares. Esses munícipios concentravam-se espacialmente em grande parte nos estados da Paraíba, Rio Grande do Norte, Sergipe e Ceará. Esse último estado merece destaque, pois no período analisado, apresentou uma grande expansão no número de municípios que apresentavam baixos percentuais de domicílios não atendidos por energia elétrica. Estes resultados servem para apontar áreas prioritárias para a expansão do acesso aos serviços de energia elétrica com o intuito de uma distribuição da energia com caráter social. Neste sentido, pode-se destacar a preocupação crescente por parte do Estado em atender a população, inclusive a localizada na zona rural, por meio do programa "Luz para todos" vinculado ao "Programa de Aceleração do Crescimento PAC 2"5.

A mortalidade infantil é um indicador que está associado às condiçóes socioeconômicas e ambientais, como, por exemplo, saneamento básico, nutrição, assistência médica, etc. A análise espacial deste indicador permite observar uma possível relação mais estreita entre o referido indicador com espaço geográfico, pois permite identificar com mais clareza aspectos demográficos, sociais, econômicos, culturais além do ambiente ligado ao meio físico.

Desta maneira, a figura 9, apresenta o diagrama de dispersão de Moran para a mortalidade infantil (por mil nascidos vivos) entre municípios nordestinos entre

5 O Programa Luz para Todos é um programa do Governo Federal do Brasil que tem como objetivo levar o acesso à energia elétrica, gratuitamente, para população do meio rural. 
os anos de 2000 e 2010. Os resultados demonstram que a maioria dos municípios encontrava-se nos quadrantes que representam a existência de autocorrelação espacial positiva, em que o valor do índice $I$ de Moran foi de 0.418349 e com um valor- $p$ $=0.001$, indicando dependência espacial do indicador avaliado, para o ano de 2000 . Para o ano de 2010, verifica-se uma redução dessa dependência espacial, porém mantendo a mesma inclinação positiva desse indicador que foi igual a 0.30823 com um valor- $p=0.001$. De maneira geral, no período analisado observa-se que a maior parte dos dados (municípios) encontrava-se nos quadrantes que representam a existência de autocorrelação espacial positiva, isto é, cidades que apresentavam um elevado número de mortalidade infantil eram circundadas por municípios com valores similares deste indicador.

\section{FIgURA 9 | I de Moran global para a mortalidade infantil do Nordeste} em 2000 e 2010

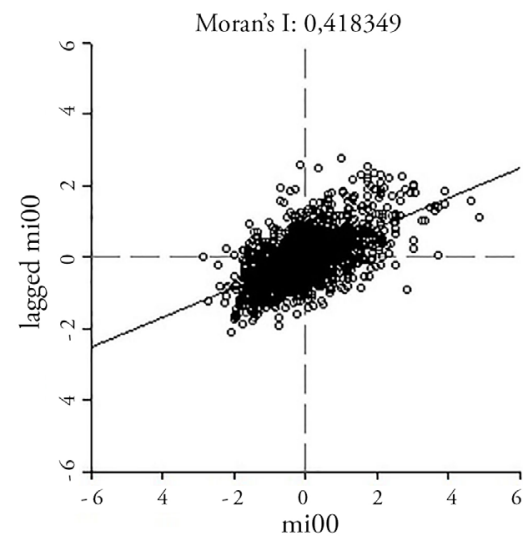

2000

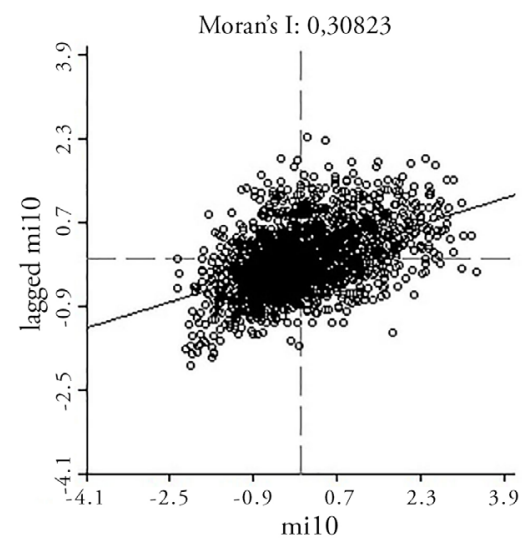

2010

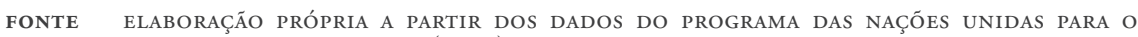
DESENVOLVIMENTO - PNUD (2OI4)

De acordo com a figura 10, encontra-se uma predominância para a classificação Alto-Alto e Baixo-Baixo. Para o ano de 2000, verifica-se uma maior concentração de municípios (241 municípios) no cluster Baixo-Baixo, localizados, predominantemente, nos estados da Bahia e Ceará. Para o estado da Bahia essa concentraçáo ocorreu principalmente nas mesorregiōes Centro Sul e Sul do estado. Já os municípios cearenses que estavam inseridos nesse agrupamento distribuíam-se espacialmente nas mesorregióes Jaguaribe e Metropolitana do estado. Ainda para o mesmo ano, havia 169 municípios que se encontravam no cluster Alto-Alto, concentrados, basicamente, nos estados do Pernambuco (principalmente, nas mesorregióes Agreste e Sertáo) e Maranhão (especialmente, nas mesorregióes Oeste e Leste).

Para o ano de 2010, houve uma redução na quantidade total de municípios inseridos no agrupamento Baixo-Baixo, entretanto, não houve uma mudança na composição espacial desse indicador, em que os municípios inseridos nesse cluster 
continuaram concentrados, principalmente, nos estados da Bahia e do Ceará. Para a Bahia verifica-se uma maior concentração desses municípios nas mesorregiôes Metropolitana e Sul, e para o Ceará, observa-se uma distribuição dessas cidades, especialmente, entre as mesorregióes Sul, Sertóes e Metropolitana do estado.

Constata-se que para o ano de 2010, o número de municípios no cluster Alto-Alto diminuiu para 157 municípios, além disso, houve uma mudança na composição dos estados que concentravam um maior número de municípios nesse agrupamento. Apesar da redução na quantidade total de municípios inseridos nesse cluster, pode-se observar que para o referido ano, o Estado do Maranháo permaneceu como sendo aquele com a maior quantidade de municípios em que se possuía uma taxa de mortalidade infantil elevada e que eram circundados por outros municípios na mesma situação. Tal concentração estava, praticamente, distribuída em quase todas as mesorregióes do estado com exceção da mesorregião sul maranhense. Também se observa, no mesmo estado, uma ampliação na quantidade de municípios inseridos no cluster Alto-Alto. Ainda para o ano 2010, verifica-se a saída do estado de Pernambuco e a entrada de Alagoas como um dos estados nordestinos com maior concentração de cidades nesse cluster, distribuídas entre as mesorregiōes Leste e Sertão alagoano.

Figura io | Clusters da mortalidade infantil do Nordeste em 2000 e 2010

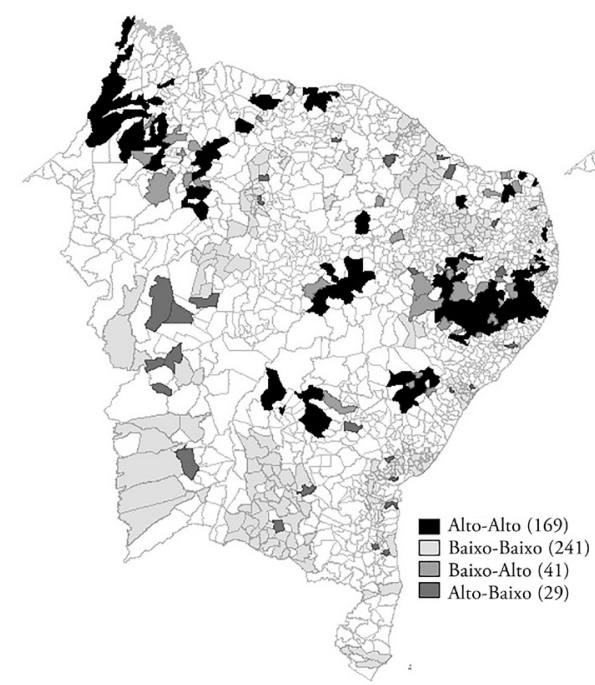

2000

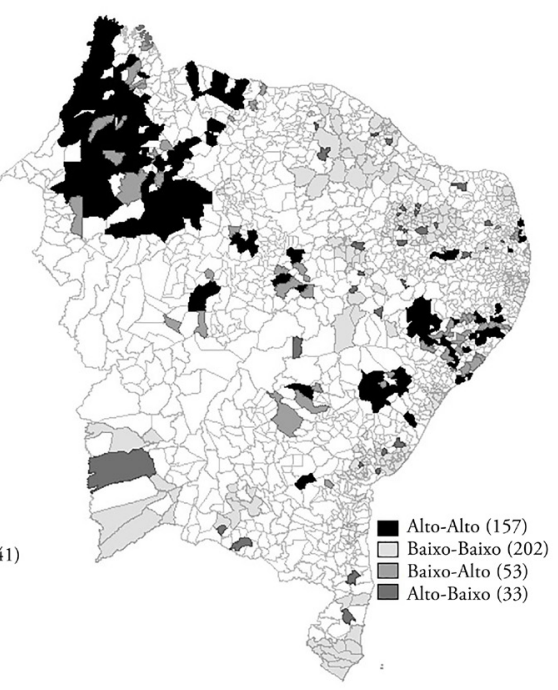

2010

FONTE ELABORAÇÁO PRÓPRIA A PARTIR DOS DADOS DO PROGRAMA DAS NAÇÓES UNIDAS PARA O DESENVOLVIMENTO - PNUD (2OI4) 


\section{Consideraçóes finais}

O presente trabalho analisou a dependência espacial dos indicadores socioeconômicos para os municípios do Nordeste brasileiro entre os anos de 2000 e 2010, por meio da análise exploratória de dados espaciais utilizando as medidas de autocorrelação espacial global (I de Moran) e de autocorrelação espacial local (Local Indicator Spatial Association - LISA). Os resultados atestaram a existência de dependência espacial positiva para todos os indicadores socioeconômicos analisados no referido estudo, formando clusters em vários pontos da região Nordeste do país.

De forma geral, verificou-se que há um evidente padrão espacial nas disparidades socioeconômicas dentro da região Nordeste, representados pela formação de vários clusters com baixo desempenho relativo a esses indicadores socioeconômicos. Dentro desse contexto, para o período analisado, observou-se que as cidades que apresentaram elevado percentual de pobreza, elevado índice de Gini, maior percentual de domicílios sem energia elétrica e as menores rendas per capitas e que eram circundados por outros municípios na mesma situação concentravam-se, principalmente, nos estados do Maranhão e Piauí, localizados, principalmente, na sub-regiáo nordestina Meio Norte. Essa sub-região representa uma faixa de transição entre a Amazônia e o Sertão Semiárido do Nordeste, sendo composta pelos estados do Maranhão e Oeste do Piauí. É uma regiāo pouco desenvolvida economicamente, em que prevalece principalmente o extrativismo vegetal, agricultura tradicional de algodáo, cana de açúcar e arroz, além da pecuária extensiva.

Por outro lado, o maior número de municípios nordestinos com baixos percentuais de pobreza e com rendas per capita elevadas e que possuíam vizinhos com condiçóes similares estavam concentrados, especialmente, nos estados da Bahia, Rio Grande do Norte e Pernambuco. Por sua vez, os municípios com valores baixo do índice de Gini e que eram circunvizinhos por cidades com indicadores equivalentes estavam distribuídos, principalmente entre os estados do Rio Grande do Norte, Paraíba e Sergipe. A grande parte desses municípios concentra-se, basicamente, na faixa litorânea pertencente à Sub-Região da Zona da Mata. Essa região apresenta a maior concentração populacional do Nordeste e é a sub-região mais urbanizada e mais desenvolvida.

São indiscutíveis as conquistas obtidas nas últimas décadas para região Nordeste como redução da pobreza, aumento da renda, forte crescimento e as modificaçóes na dinâmica econômica. Entretanto, deve-se admitir que a trajetória histórica desta região ainda revela resistentes padróes de desigualdades sócio espaciais.

Os resultados obtidos até aqui nos fazem refletir sobre a necessidade de melhorar a eficácia desses instrumentos adotados e abrem espaço para propor estratégias de desenvolvimento mais efetivas e intervençóes públicas no foco do problema, levando em consideração as particularidades de cada regiáo, impulsionando potencialidades de desenvolvimento local. 


\section{Referência bibliográfica}

Almeida, E. (2012). Econometria espacial aplicada. Campinas, São Paulo: Editora Alínea.

Anselin, L. (1995). Local Indicators of Spatial Association - LISA. Geographical Analysis, 27(2), 93-115. http://dx.doi.10.1111/j.1538-4632.1995.tb00338.x

Anselin, L. (1988). Spatial Econometrics: Methods and Modes. Dordrecht, Países Bajos: SpringerScience+Business Media B.V. http://dx.doi.10.1007/978-94-015-7799-1

Araújo, T. B. de. (2014). Nordeste: desenvolvimento recente e perspectivas. In P. F. Guimarães et al. (Orgs.), Um olhar territorial para o desenvolvimento: Nordeste (pp.540-560). Rio de Janeiro: Banco Nacional de Desenvolvimento Econômico e Social.

Araújo, T. B. de. (2008). Nordeste: heranças, oportunidades e desafios. São Paulo: Revista Teoria e Debate, (77). Disponível em www.teoriaedebate.org.br

Araújo, T. B. de. (2002). Nordeste, Nordestes: que Nordeste? Recife: Fundação Joaquim Nabuco (Fundaj). Disponível em http://www.fundaj.gov.br/observanordeste/obte013.doc

Araújo, T. B. de. (2000). Ensaios sobre o desenvolvimento brasileiro: heranças e urgências. Rio de Janeiro: Revan/Fase.

Caldas, R. M. \& Lima, J. P. R. (2008). Análise das microrregiōes nordestinas com sinais potenciais de aglomeraçôes produtivas. Revista Brasileira de Estudos Regionais e Urbanos, 02, 130-154. Disponível em http://bit.ly/2pCrlOy

Genovez, P. C. (2002). Território e desigualdade: análise espacial intra-urbana no estudo da dinâmica de exclusão/inclusão social no espaço urbano em São José dos Campos. São Dissertação de Mestrado, Instituto Nacional de Pesquisa Espacial, São Paulo, Brasil.

Gumiero, R. G. O. (2014). Nordeste em dois tempos: a "Operação Nordeste" e a Política de Desenvolvimento Regional do Governo Lula. Serie Documentos de Proyectos No 585 [LC/W.585]. Santiago, Chile: Comissáo Econômica para a América Latina e o Caribe (CEPAL). Disponível em http://repositorio.cepal.org/handle/11362/36674

Instituto de Pesquisa Econômica Aplicada (IPEA). Disponível em http://www.ipeadata.gov.br/

Lima, A. C. C. \& Lima, J.P.R. (2008). Economia do Nordeste: evoluçáo do emprego na indústria de transformação e extrativa mineral e identificação de aglomeraçôes produtivas. Revista Econômica do Nordeste, 39(3), 503-531.

Oliveira, F. de. (1981). Elegia para uma re(li)gião: Sudene, Nordeste. planejamento e conflitos de classes. (3aed.). Rio de Janeiro: Paz e Terra.

Pereira, E. M. (2015). Desenvolvimento, questão social e Nordeste brasileiro: contradiçóes e tendências atuais. Temporalis, 2(30), 281-306. Disponível em https://dialnet.unirioja. es/ejemplar/412390

Pereira Junior, E. (2012). Território e economia politica: uma abordagem a partir do novo processo de industrialização no Ceará. São Paulo: Cultura Acadêmica.

Pereira, F. K. R. \& Porto Junior, S. S. (2001). Desigualdade regional de renda no Brasil-Análise e previsão. Estudos do Centro de Estudos e Pesquisa de Economia da Universidade Santa Cruz do Sul (CEPE), no 14, 29-52. Santa Cruz do Sul, Brasil.

Programa das Naçóes Unidas para Desenvolvimento (PNUD) (2013). Atlas de desenvolvimento humano no Brasil. Disponível em http://www.atlasbrasil.org.br/2013/ 
Santos, M. (2001). Quem está na frente é o povo. Entrevista concedida a Carlos Tibúrcio e Sílvio Caccia Bava. Especial no 2: Um outro mundo urbano é possível. Cadernos Le Monde Diplomatique. São Paulo, Instituto Abaporu, p. 4-7, jan. Edição especial. n², pp. 4-7.

Teague, P. \& Wilson, R. (1995). Towards an inclusive society. InSocial exclusion, Social inclusion. Report $N^{\circ} 2$ (pp. 79-97). Belfast, uk: Democratic Dialog.

Teixeira, M. S. G. \& Pequeno, R. S. A. (2009). O Nordeste Brasileiro: um espaço em retalhos. In Encontro Nacional e Economia Regional VII ENABER, 2009, São Paulo. Anais do VII ENABER. Disponível em http://aplicativos.fipe.org.br/enaber/pdf/56.pdf

Theis, I. M. \& Galvão, A. C. F. (2012). A formulaçáo de políticas públicas e as concepçôes de espaço, território e regiấo. Revista Brasileira de Estudos Urbanos e Regionais, 14(2), 55-69. http://dx.doi.org/10.22296/2317-1529.2012v14n2p55 